\title{
Aetiology and presentation of childhood pleural infections in the post-pneumococcal conjugate vaccine era in South Africa
}

\author{
L Golden, ${ }^{1}$ MB BCh, FCPaed (SA), MMed; S Chaya, ${ }^{1,2}$ MB BCh, FCPaed, MMed, Cert Paed Pulm; K Reichmuth, ${ }^{1}$ MB ChB, MPH; \\ A Visagie, ${ }^{1,2}$ BTech; A Ayuk, ${ }^{1}$ MB BS, FMC Paed, MPhil Paed Pulm, Cert Paed Pulm; \\ S Kwarteng Owusu, ${ }^{1,3}$ MB ChB, FWACP, GCPS, Cert Paed Pulm; D Marangu, ${ }^{1,4}$ MB ChB, MMed, MPH, MPhil, Cert Paed Pulm, PhD; \\ N Affendi, ${ }^{1,5}$ MD, MMed; A Lakhan, ${ }^{1}$ MB ChB, FCPaed, MMed; D Gray, ${ }^{1}$ MB ChB, FRACP (Paed), MPhil (Paed Pulm), PhD; \\ A Vanker, ${ }^{1} \mathrm{MB}$ ChB, FCPaed, MMed, Cert Paed Pulm, PhD; H Zar, ${ }^{1,2}$ MB BCh, FRCPaeds, FRCP, ATSF, FAPSR, MD, PhD; \\ M Zampoli, ${ }^{1} \mathrm{MB}$ BCh, FCPaed, Cert Paed Pulm \\ ${ }^{1}$ Department of Paediatrics and Child Health, University of Cape Town and Red Cross War Memorial Children's Hospital, Cape Town, South Africa \\ ${ }^{2}$ MRC Unit for Child and Adolescent Health, University of Cape Town, South Africa \\ ${ }^{3}$ Komfo Anokye Teaching Hospital, Department of Child Health, Kwame Nkrumah University of Science and Technology, Kumasi School of Medicine and \\ Dentistry, Ghana \\ ${ }^{4}$ Kenyatta National Hospital, Department of Paediatrics and Child Health, University of Nairobi, Kenya \\ ${ }^{5}$ Department of Paediatrics, Hospital Sultanah Nur Zahirah, Terengganu, Malaysia
}

Corresponding author: L Golden (goldenlme@gmail.com)

\begin{abstract}
Background. Complications of respiratory infections including pleural effusion (PE) are associated with a high morbidity. Differentiating between PE caused by Mycobacterium tuberculosis (Mtb) infection and other bacterial infections in endemic areas is difficult in children, thus, impacting treatment.

Objective. To investigate the aetiology of PE and features distinguishing tuberculosis (TB) from bacterial PE in children.

Methods. We conducted a prospective study in children with PE admitted to a tertiary hospital in Cape Town from December 2017 to December 2019. Clinical information and routine laboratory investigations were compared between children with bacterial, Mtb or unclassified PE, categorised according to study definitions.

Results. A total of 91 patients were included in the present study and their median age was 31 months (interquartile range (IQR) 11.8 102.1). The aetiology was bacterial in $40 \%(n=37)$, Mtb in $39 \%(n=36)$ and unclassified in $20 \%(n=18)$ of patients. Staphylococcus aureus was the most common bacterial isolate, confirmed in $65 \%(n=24 / 37)$ patients, and Streptococcus pneumoniae was confirmed in only $8 \%$ of patients. TB was microbiologically confirmed in $33 \%(n=12 / 36)$ of patients. Patients with TB were older (91.6 v. 11.8 months; $p<0.001)$, with more weight loss ( $28 \mathrm{v} .12$ patients; $p<0.001)$, and longer cough duration $(10 \mathrm{v}$. 4 days; $p<0.001)$ than those with other bacterial PE. In contrast, the latter had significantly higher serum C-reactive protein (median $250 \mathrm{v} .122 \mathrm{mg} / \mathrm{L} ; p<0.001$ ), procalcitonin ( $11 \mathrm{v} .0 .5 \mathrm{mg} / \mathrm{L}$; $p<0.001$ ), pleural fluid lactate dehydrogenase (7 $280 \mathrm{v} .544 \mathrm{U} / \mathrm{L} ; p<0.001)$, and adenosine deaminase levels $(162 \mathrm{v} .48 \mathrm{U} / \mathrm{L} ; p<0.001)$ and lower glucose levels (1.3 v. $4 \mathrm{mmol} / \mathrm{L} ; p<0.001)$.

Conclusion. Post 13-valent pneumococcal conjugate vaccine, $S$. aureus is the dominant cause of PE in children using traditional culture methods, while Mtb remains a common cause of PE in our setting. Useful clinical and laboratory differences between Mtb and other bacterial $\mathrm{PE}$ were identified, but the cause of PE in $20 \%$ of children was underdetermined. Molecular testing of pleural fluid for respiratory pathogens may be useful in such children.

Keywords. pleural effusion; empyema; tuberculosis; pneumococcal conjugate vaccine.
\end{abstract}

Afr J Thoracic Crit Care Med 2021;27(4):138-144. https://doi.org/10.7196/AJTCCM.2021.v27i4.152

Acute respiratory infections are a leading cause of childhood mortality globally, ${ }^{[1,2]}$ and the second highest cause (10\%) of mortality in South African (SA) children $<5$ years. ${ }^{[3]}$ Pleural effusions (PE) are recognised complications of pneumonia, resulting in increased hospital stay, morbidity and mortality. ${ }^{[4]} \mathrm{A}$ causative organism is often not identified using routine culture techniques, with up to $60 \%$ of cases having no bacteriological identification. ${ }^{[5,6]}$ When a causative organism is found, the most common pathogens are Streptococcus pneumoniae, Staphylococcus aureus and Group A Streptococcus spp. such as S. pyogenes. Following the introduction of the 13-valent pneumococcal conjugate vaccine $(\mathrm{PCV})$, there has been an overall decrease in invasive pneumococcal disease and complicated pneumococcal pneumonia, including PE. ${ }^{[7-9]}$ Molecular polymerase chain reaction (PCR) techniques targeting common respiratory pathogens increase the detection rates of respiratory pathogens, specifically $S$. pneumoniae, by up to three times more than culture. ${ }^{[5,7,8]}$ However, these tests are not yet routinely available in developing countries, thus limiting the interpretation of studies reporting PE aetiology using culture-only techniques.

Mycobacterium tuberculosis (Mtb) is another leading cause of pneumonia in SA and other developing countries, with SA reporting one of the highest incidences of tuberculosis (TB) globally (520 cases/ 100000 population), with children making up $7 \%$ of new cases. ${ }^{[10]}$ 
A serous, straw-coloured PE is a common manifestation of pleural TB in adults and children, and $\mathrm{TB}$ is a common cause of $\mathrm{PE}$ in endemic settings. Tuberculous empyema, however, is uncommon but reported to be the third most common cause of empyema in SA, occurring in 10 - $14 \%$ of empyema cases. ${ }^{[7,8]}$ Diagnosis of TB is challenging in children due to the paucibacillary nature of the disease and difficulty in obtaining suitable samples. Despite advances in the diagnosis of TB, culture remains the gold standard in children, which may result in missed or delayed diagnosis. Molecular techniques such as Xpert MTB/RIF and Xpert MTB/RIF-Ultra on respiratory samples are more sensitive than microscopy in identifying TB and have improved early diagnosis of pulmonary TB in adults and children. ${ }^{[11-14]}$ However, the sensitivity of Xpert MTB/RIF on pleural fluid is low, reported to be $50-55 \% .^{[13,15-18]}$ Children with PE in SA and other developing countries are therefore often started on empiric TB treatment without confirmation of TB, as described in a SA study where $43 \%$ of children with PE were empirically initiated on TB treatment. ${ }^{[9]}$

With limited microbiological or laboratory confirmation of aetiology, clinicians in SA and similar developing countries rely on a combination of clinical, biochemical, and radiological features to determine the aetiology of $\mathrm{PE}$ in children. Our study aimed to investigate the incidence and aetiology of infective PE in children using routine microbiological methods, and to compare clinical and laboratory characteristics and outcomes of PE caused by bacterial infections and TB.

\section{Methods \\ Study design, setting and recruitment}

This prospective, descriptive observational study was conducted at Red Cross War Memorial Children's Hospital (RCWMCH), a tertiary referral hospital in Cape Town, SA. Children younger than 13 years who were admitted with PE from December 2016 to December 2019 were enrolled in the present study if they had PE identified clinically and radiographically. Patients with PE due to trauma or following any surgical procedure; transudative PE due to cardiac, renal or liver disease, or other non-infective aetiologies; PE associated with nosocomial infection (defined as PE associated with onset of new infection after $48 \mathrm{~h}$ after admission to hospital); or those where written informed consent or assent was not obtained; and patients in whom pleural fluid sample was not obtainable were excluded from the study. Written informed consent from parents and assent (in children $>7$ years) were obtained in all patients. Pleural fluid samples were collected by pleural space aspiration or pleural drainage performed using an aseptic technique.

\section{Data collection methods}

A data collection form was used by investigators for all patients at enrolment in the study. Data were entered into and managed using Research Electronic Data Capture (REDCap), an online electronic data capture tool hosted at the University of Cape Town.

\section{Clinical data and interventions}

Demographic data, clinical symptoms and signs at presentation, immunisations record for PCV, and World Health Organization referenced weight-for-age (WFA) Z-scores were collected. Weight loss data were either self-reported or clinically assessed. The following interventions and outcome data were recorded: type and duration in situ of a chest drain, if needed; the use of fibrinolysis; the need for surgical drainage; the duration of hospitalisation; the need for ICU admission; and mortality data.

\section{Investigations}

A chest radiograph was performed on all patients at admission, and a chest ultrasound was requested at the discretion of the treating clinicians.

Routine laboratory investigations were performed on blood and pleural fluid samples. Haematology and biochemical blood investigations included a full blood count (FBC), white cell (WCC) differential count, serum lactate dehydrogenase (LDH), total protein, albumin, C-reactive protein (CRP), and procalcitonin (PCT). HIV testing was done in all patients. HIV antibody testing was performed in all patients in whom HIV status was not known, and in HIVunexposed patients. HIV PCR testing was performed in HIV-exposed children under the age of 18 months, and HIV antibody testing in those older than 18 months. Pleural fluid sample investigations included macroscopic appearance (purulent or turbid, straw coloured, blood stained or bloody), glucose, total protein, $\mathrm{LDH}$, and adenosine deaminase (ADA). Cytology and cell count were performed where available. Microbiological tests included blood culture and pleural fluid bacterial and TB cultures using standard culture techniques, as well as Xpert MTB/RIF or Xpert MTB/RIF-Ultra on pleural fluid samples. All patients had a tuberculin skin test (TST) and at least two induced sputum samples collected for Xpert MTB/RIF or Xpert MTB/ RIF -Ultra and TB culture.

\section{Aetiological definitions}

The aetiology of PE was categorised as confirmed or unconfirmed bacterial, TB, or unclassified, according to the following study-defined clinical definitions:

Confirmed TB: ${ }^{[19]}$ microbiological confirmation of TB by positive Xpert MTB/RIF or Xpert MTB/RIF - Ultra or positive TB culture from induced sputum and/or pleural fluid.

Unconfirmed TB: ${ }^{[19]}$ microbiological confirmation of TB was not obtained and at least two of the following were present: persistent cough $>2$ weeks, weight loss or WFA $<2$ standard deviations (SD) below the mean $Z$-score, household TB contact exposure, or positive TST result (defined as a TST reading at $48-72 \mathrm{~h}$ of $\geq 10 \mathrm{~mm}$ in HIVnegative patients, or $\geq 5 \mathrm{~mm}$ in HIV-positive patients).

Confirmed bacterial: patients with pleural effusion who had microbiologically confirmed (pleural fluid or blood culture) bacterial infection.

Unconfirmed bacterial: absence of culture confirmation on blood and/or pleural fluid but supporting laboratory evidence of bacterial infection of pleural fluid, i.e. pus or purulent pleural fluid on macroscopic inspection, neutrophil predominance of pleural fluid, and absence of clinical features of TB as per above definitions.

Unclassified: patients who did not meet the definitions for TB or other bacterial infection.

\section{Data analysis}

The annual incidence rate of bacterial PE per 1000 lower respiratory tract infection admissions at the hospital from 2017 - 2019 was calculated by extracting data from the hospital electronic International 
Classification of Disease (ICD) 10-coded admissions database. This formula was selected for comparison to previous incidence data at our hospital and excluded TB cases. ${ }^{[7]}$

Data were analysed using Stata statistical software, version 13 (StataCorp, USA). The mean with standard deviation (SD) and median with interquartile range (IQR) were used to describe normally and non-normally distributed continuous data, respectively. Means were compared between aetiological groups using one-way ANOVA; the Bonferroni correction for multiple comparisons was applied. Medians were compared between aetiological groups using the Kruskal-Wallis test; two-sample Wilcoxon rank sum tests were used to identify differences between each pair of groups. Categorical data were compared between aetiological groups using $\chi^{2}$ or Fisher's exact tests, as appropriate. A $p<0.05$ was considered statistically significant.

\section{Ethics}

Ethical approval was obtained from the Human Research Ethics Committee of the University of Cape Town (ref. no. HREC REF $6.61 / 2019)$.

\section{Results}

\section{Study population and aetiological classification}

Of the 117 children screened, 91 patients with a median age of 31 months (IQR 11.8 - 102.1) were enrolled. Less that two-thirds of children were male $(61 \% ; n=56)$, and $15 \%(n=14)$ were HIVexposed, four of whom were HIV-positive. We excluded 26 patients for lack of consent $(n=6)$, pleural sample collection was not possible $(n=6)$, remote geographical home location or transfer out of facility $(n=3)$, PE related to nosocomial infection $(n=3)$, and PE related to other causes, e.g. malignancy or transudate $(n=8)$. Demographic characteristics and clinical features of enrolled patients are displayed in Table 1. Aetiology (confirmed and unconfirmed) was classified as bacterial in $40 \%(n=37)$, TB in $40 \%(n=36)$ and unclassified in $20 \%$ $(n=18)$ patients. Fig. 1 shows a detailed breakdown of aetiological categories.

Cough was the most common presenting symptom reported in $89 \%$ of patients, followed by shortness of breath and fever in $67 \%$ and $65 \%$ of patients, respectively. The mean (SD) WFA Z-score was -0.195 (1.510). HIV testing was performed in all patients: $84.6 \%(n=77 / 91)$ were HIV-negative, $11 \%(n=10 / 91)$ were currently exposed but were HIV uninfected, and $4.4 \%$ of patients $(n=4)$ were infected with HIV.

Compared with the bacterial group, patients with TB were older (91.6 v. 11.8 months; $p<0.001$ ), more reported weight loss ( 28 v. 12 patients; $p<0.001)$ and chest pain ( $22 \mathrm{v} .7$ patients; $p<0.001)$, and had a longer cough duration (10 v. 4 days; $p=0.01$ ) (Table 1$)$.

\section{Aetiology}

The mean incidence of bacterial PE during our study period was 5.6 cases per 1000 cases of lower respiratory tract infection admitted (range 2.6 - 7.9) (Table 2). Among the bacterial group, 45\% ( $n=14 / 31)$ of blood and $68 \%(n=25 / 37)$ of pleural fluid samples were culture positive. S. aureus was the most common bacterial isolate, confirmed in $65 \%(n=24 / 37)$ of patients; all isolates were sensitive to cloxacillin. Other organisms isolated were S. pneumoniae $(8 \% ; n=3 / 37)$, $S$. pyogenes $(5 \% ; n=2 / 37), S$. constellatus $(n=1)$ and anaerobes $(5 \%$; $n=2$ ), one of the anaerobes as a co-infection with TB (Fig. 2).
Overall, $42 \%$ ( $n=39 / 91)$ of participants were fully vaccinated with three doses of PCV while $54 \%(n=20 / 37)$ of the bacterial group were fully vaccinated with PCV. Two of the three confirmed S. pneumoniae cases were fully vaccinated for PCV and one was partially vaccinated with two doses due to young age.

Among the TB group, microbiological confirmation by Xpert MTB/RIF and Xpert MTB/RIF-Ultra or TB culture was possible in $33 \%(n=12 / 36)$ of patients. Less than a quarter of patients $(14 \% ; n=5)$ had pleural fluid that was Xpert MTB/RIF or Xpert MTB/RIF-Ultra positive, and TB culture positive in $22 \%(n=8)$ of the cases (Table 3$)$. The TST result was positive in $67 \%, 11 \%$, and $0 \%$ of TB, unclassified, and bacterial PE cases, respectively. One case had confirmed TB and bacterial co-infection.

\section{Laboratory investigations}

Table 4 describes selected laboratory findings across the bacterial, TB and unclassified groups. Statistically significant differences were observed in median values of laboratory indices between bacterial and TB groups: WCC, neutrophil count, CRP, PCT, LDH and ADA was higher in the bacterial group compared with the TB group, and glucose was lower in the bacterial group compared with TB group while total protein was similar between the groups. Overall, clinical and laboratory findings of the unclassified group fell between those of the TB and bacterial groups. Macroscopic appearance of pleural fluid was purulent in $78 \%(n=29 / 37)$ of total bacterial group patients, and $74 \%(n=23 / 31)$ of the confirmed bacterial patients. Of the TB group of patients, $42 \%(n=5 / 12)$ of the confirmed TB patients also had purulent effusions, but none of the unclassified group had this finding. Cytology was negative for malignancy in all patients.

\section{Interventions and outcomes}

Overall, $80 \%(n=74)$ of patients had a chest drain inserted, which included $100 \%(n=37)$ of the bacterial group. The median (IQR) duration of chest drain use was $5(3.5-6.0)$ days, and $49 \%$ of patients received intrapleural fibrinolysis, including $17 \%(n=6)$ in the TB group. Bacterial infection was associated with higher rates of intensive care unit admission (19\%; $n=7)$ and surgical drainage $(27 \%$; $n=10)$ compared with the TB and unclassified groups. The median (IQR) length of hospital stay was 8.5 (5 - 13) days and was higher in the bacterial and unclassified groups. There was one death in the unclassified group - the patient was a 20-month-old boy, HIVunexposed, who had a negative TST and was fully vaccinated with PCV. He died due to acute respiratory distress syndrome. Table 5 provides further detailed results of interventions and outcomes.

\section{Discussion}

\section{Incidence and aetiology}

Our study documented the incidence and aetiology of PE in SA in the post-PCV era. The mean incidence of 5.6 per 1000 pneumonia admissions of PE due to bacterial infections was similar to previous findings from the same centre in $2015 \cdot{ }^{[7]}$ In that study, the incidence declined from 10.4 to 4.2 cases per 1000 pneumonia admissions after PCV was introduced, and our present study confirms the sustained effect of PCV in preventing pneumococcal-associated PE. ${ }^{[7]}$

We found that the majority of PE $(80 \%)$ in children could be classified as either bacterial infection or TB, occurring with equal 
Table 1. Demographic and clinical data

\begin{tabular}{|c|c|c|c|c|c|}
\hline & $\begin{array}{l}\text { Bacterial, } \\
n(\%)^{*}\end{array}$ & $\begin{array}{l}\text { TB, } \\
n(\%)^{*}\end{array}$ & $\begin{array}{l}\text { Unclassified, } \\
n(\%)^{*}\end{array}$ & $\begin{array}{l}\text { Total, } \\
n(\%)^{*}\end{array}$ & $p$-value \\
\hline & $37(40.6)$ & $36(39.6)$ & $18(19.8)$ & 91 & \\
\hline \multicolumn{6}{|l|}{ Demographics } \\
\hline Age (months), median (IQR) & $11.8(7.2-25.5)$ & $91.6(49.8-125.6)$ & $30.7(19.6-100.6)$ & $31.3(11.8-102.1)$ & $<0.001$ \\
\hline Sex male & $23(62.2)$ & $21(58.3)$ & $12(66.7)$ & $56(61.5)$ & 0.843 \\
\hline HIV-exposed & $9(24.3)$ & $3(8.3)$ & $2(11.1)$ & $14(15.4)$ & 0.142 \\
\hline HIV-infected & $1(2.7)$ & $1(2.8)$ & $2(11.1)$ & $4(4.4)$ & 0.321 \\
\hline \multicolumn{6}{|l|}{ Clinical features } \\
\hline Cough & $29(78.4)$ & $26(72.2)$ & $16(88.9)$ & $16(88.9)$ & 0.377 \\
\hline Cough duration (days), median (IQR) & $4(3-7)$ & $10(4-21)$ & $5(3-7)$ & $5(3-10)$ & 0.012 \\
\hline Shortness of breath & $28(75.7)$ & $21(58.3)$ & $12(66.7)$ & $12(66.7)$ & 0.289 \\
\hline TB exposure in past 6 months & $2(5.4)$ & $10(28.6)$ & $1(5.6)$ & $1(5.56)$ & 0.01 \\
\hline Weight loss & $12(32.4)$ & $28(77.8)$ & $3(16.7)$ & $43(47.3)$ & $<0.001$ \\
\hline Chest pain & $7(18.9)$ & $22(61.1)$ & $5(27.8)$ & $34(37.4)$ & $<0.001$ \\
\hline Antibiotics in the last 7 days & $20(54.0)$ & $16(44.4)$ & $14(77.8)$ & $50(55.0)$ & 0.067 \\
\hline WAZ, mean (SD) & $0.166(1.539)$ & $-0.815(1.361)$ & $0.015(1.444)$ & $-0.195(1.510)$ & 0.049 \\
\hline WAZ $<-2 S D$ & $2(5.4)$ & $4(11.1)$ & $1(5.6)$ & $7(7.7)$ & 0.126 \\
\hline Pyrexia $>38^{\circ} \mathrm{C}$ & $25(67.6)$ & $23(63.9)$ & $11(61.1)$ & $59(64.8)$ & 0.885 \\
\hline Pneumothorax & $7(18.9)$ & $1(2.86)$ & $3(16.7)$ & $11(12.2)$ & 0.071 \\
\hline
\end{tabular}

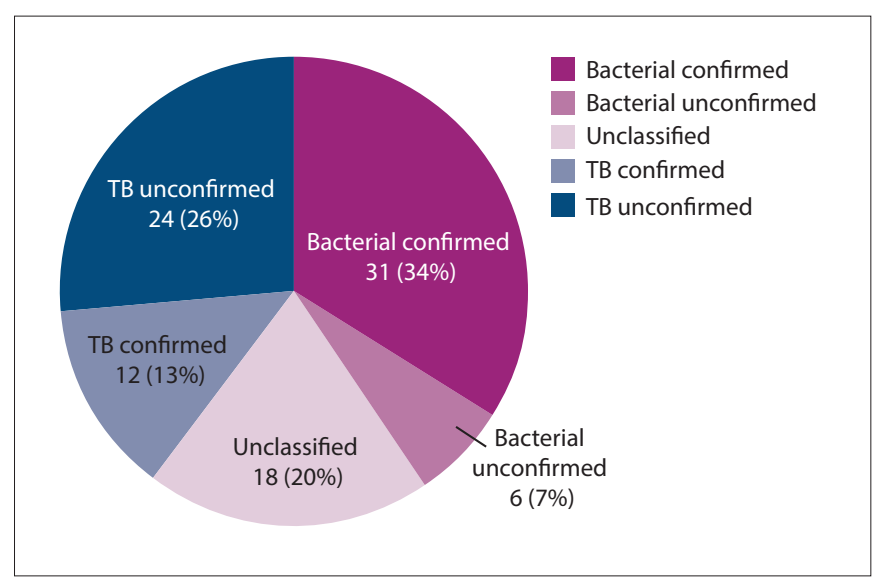

Fig. 1. Pleural effusion and empyema by aetiological categories (n (\%)).

frequency ( $40 \%$ each). S. aureus was the most common bacterial pathogen isolated on blood and pleural fluid cultures (65\% of all bacterial cases), with low rates of $S$. pneumoniae, which was isolated in only $8 \%$ of the cases. This is consistent with findings from other studies using traditional culture-based methods for diagnosis in our setting. ${ }^{[7]}$ Of the 91 enrolled patients in the present study, complete vaccination with three doses of PCV was documented in $42 \%$ of the participants, and only $54 \%$ of bacterial PE cases. The lower median age of patients in the bacterial group (11 months; IQR 7 - 25) may partly account for low numbers having completed the PCV vaccination schedule in the bacterial group, as the third PCV dose is given at 9 months of age in the SA immunisation programme. ${ }^{[20]}$ Although we documented a sustained decline in bacterial PE cases in our centre, the true incidence of $S$. pneumoniae infections may be underestimated in the absence of molecular testing, which is more sensitive than culture for detecting bacterial pathogens. ${ }^{[8,21]}$ Two of the three S. pneumoniae isolates in this present study occurred in patients who were fully vaccinated with PCV. The presence of non-vaccine-related S. pneumoniae serotype disease in this cohort could not be excluded. All $S$. aureus isolates in our study were sensitive to Cloxacillin. This is reassuring and consistent with findings in previous studies in this setting ${ }^{[8]}$ and affirms that widespread methicillin-resistant S. aureus is not present in our setting. These bacterial aetiology findings have important implications for clinicians, highlighting the need to ensure that $S$. aureus treatment is adequately covered in the empiric antibiotic management of PE in our setting. This finding also supports the growing body of evidence which suggests that $S$. aureus empyema is increasing following access to PCV, which may represent an unintended negative consequence of access to PCV ${ }^{[5,6]}$ Our study found only one case of $S$. pyogenes, and thus did not support findings elsewhere of selection of Group A Streptococcus spp. post PCV. ${ }^{[5,6]}$

A high percentage of bacterial group patients (78\%) had purulent effusions on macroscopic exam, which indicates Stage 3 PE or empyema at presentation. Although we did not distinguish bacterial parapneumonic effusions and empyema for the purposes of analysis, these data show that most of the bacterial group patients had empyema, as did $42 \%$ of TB group patients. Other pleural fluid investigations in the bacterial group are interpreted considering this.

The high percentage of $\mathrm{PE}$ due to TB in our present study reflects the high incidence of TB in the population. ${ }^{[10]}$ It is also consistent with other paediatric studies in our setting. ${ }^{[7,9]}$ One such study described an unexpected finding of $14 \%$ confirmed TB cases in a paediatric empyema study where suspected TB cases were actively excluded at enrolment, ${ }^{[7]}$ and another showed that $43 \%$ of empyema study cases were empirically treated for TB based on clinical features. ${ }^{[9]}$ This highlights the need for judicious screening for TB in all patients with 
Table 2. Incidence of PE and empyema due to bacterial infections, 2017 - 2019

\begin{tabular}{llll}
\hline Years & PE cases enrolled, & Total pneumonia admissions, & $\begin{array}{l}\text { PE incidence per } \mathbf{1} 000 \text { pneumonia admissions per year, } \\
\boldsymbol{n}(\mathbf{9 5 \%} \mathbf{C I})\end{array}$ \\
\hline 2017 & 21 & 2675 & $7.9(4.9-12)$ \\
2018 & 9 & 3487 & $2.6(1.0-4.9)$ \\
2019 & 21 & 3355 & $6.3(3.9-9.6)$ \\
Total & 51 & 9517 & $5.4(4.0-7.1)$ \\
PE = pleural effusion; CI = confidence interval. & &
\end{tabular}

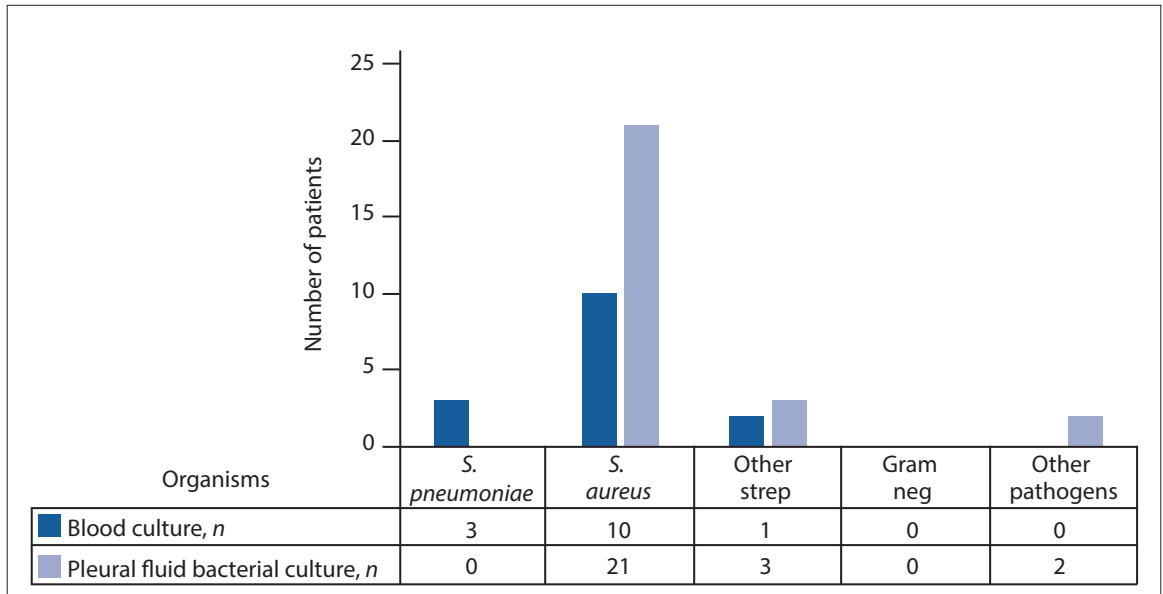

Fig. 2 Aetiological results of bacterial cultures. (S. pneumoniae = Streptococcus pneumoniae; $\mathrm{S}$. aureus $=$ Staphylococcus aureus; $\mathrm{Neg}=$ negative $)$.

$\mathrm{PE}$, and the diagnostic challenge of excluding TB in children. Xpert MTB/RIF and Xpert MTB/RIF-Ultra were positive in $14 \%(n=5)$ of pleural specimens, and TB culture detected TB in 22\% $(n=8)$ of cases. This confirms the low sensitivity of Xpert MTB/RIF in pleural fluid as reported by Scott et al. ${ }^{[15]}$ in a large study on the diagnostic performance of Xpert MTB/RIF on extrapulmonary specimens. One patient was co-infected with Mtb and bacterial PE. This finding was lower than previously reported ${ }^{[7,9]}$ in PE and pneumonia studies in SA. ${ }^{[22]}$ However, molecular-based testing for bacterial pathogens may reveal more TB-bacterial co-infected patients.

Using our present study definitions, we categorised the aetiology of PE as bacterial or TB in $80 \%$ of patients. However, $20 \%$ of patients did not fulfil the criteria for either category and were categorised as unclassified. The unclassified group had clinical and laboratory characteristics in between those of the TB and bacterial group, with a greater proportion of patients receiving antibiotics prior to presentation (78\%) compared with the other groups (TB group $44 \%$ and bacterial group 54\%). Although not statistically significant, this trend of increased pre-admission antibiotic treatment suggests that the unclassified group could represent partially treated, culture-negative bacterial PE. The unclassified group also did not have any patients with purulent pleural effusion on macroscopic exam, which may support the theory of this group being culture-negative bacterial PE. Alternatively, the unclassified group may represent TB-bacterial coinfected patients. In practice, this unclassified group will therefore derive most benefit from using routine molecular diagnosis to identify a bacterial pathogen in culture-negative pleural fluid samples to guide appropriate antibiotic treatment, and simultaneously avoid unnecessary TB treatment. Clinical and laboratory comparisons of the bacterial and $\mathrm{TB}$ groups in this present study revealed features that could be helpful in differentiating the two groups. Older age, chronic symptoms and history of $\mathrm{TB}$ exposure were more common in children in the TB group; and CRP, PCT, pleural LDH and ADA levels were significantly higher in the bacterial group compared with the other groups. These patterns are thus helpful in practice if the diagnosis is still uncertain during management of PE cases. This study also highlights that in up to $20 \%$ of cases where the aetiology is unclassifiable, the role of these clinical and laboratory features is limited.

The finding of a high pleural ADA in bacterial PE (median (IQR) 116.2 (59.2 - 275)) compared with the TB group (median (IQR) $47.1(41.3-58.2)$ ) is of interest, as an elevated pleural ADA is known to be a diagnostic test for TB-associated $\mathrm{PE}$, especially in TB-endemic settings. ${ }^{[23-24]}$ However, high pleural ADA levels have also been previously reported in empyema in paediatric and adult studies, so this finding is not unexpected. ${ }^{[24-25]}$ A 2004 review of diagnostic biochemical markers of $\mathrm{PE}$ in the paediatric population by Segura ${ }^{[26]}$ found that exudative PE with lymphocytic predominance and high pleural ADA is most likely due to $\mathrm{TB}$, while high pleural ADA in neutrophilpredominant PE suggests parapneumonic effusion, particularly empyema, as is the case in our present study.

\section{Interventions and outcomes}

As expected, patients with bacterial PE needed more interventions (chest drains, fibrinolysis, surgical drainage) compared with those with TB-associated PE. Pre-emptive fibrinolytic therapy is the preferred protocol at $\mathrm{RCWMCH}$ for patients with bacterial $\mathrm{PE}$, as it decreases hospital stay, has similar efficacy to video-assisted thoracoscopic surgery, and decreases the need for surgical drainage. ${ }^{[8,27]}$ The fact that six TB patients received fibrinolysis highlights the difficulty of distinguishing $\mathrm{TB}$ and bacterial infection at the time of presentation. More than twothirds of patients (74\%) across all groups had a chest drain inserted. This high number may reflect the large percentage of patients with advanced and severe PE enrolled in the present study (78\% of bacterial PE and $42 \%$ of TB PE had purulent/stage $3 \mathrm{PE}$ ). Local practice is also to drain large symptomatic TB pleural effusions for symptomatic relief, which is a contributing factor to the high rate 
Table 3. TB investigations on pleural fluid

\begin{tabular}{|c|c|c|c|c|}
\hline $\begin{array}{l}\text { Pleural fluid Xpert } \\
\text { MTB/RIF }\end{array}$ & $\begin{array}{l}\text { Negative, } \\
n\end{array}$ & $\begin{array}{l}\text { Positive, } \\
n\end{array}$ & $\begin{array}{l}\text { Contaminated, } \\
n\end{array}$ & $\begin{array}{l}\text { Not done, } \\
n\end{array}$ \\
\hline Negative & 72 & 4 & 4 & 3 \\
\hline Positive & 1 & 4 & 0 & 0 \\
\hline Not done & 1 & 0 & 2 & 3 \\
\hline
\end{tabular}

Table 4. Comparison of selected laboratory findings in bacterial, TB and unclassified groups

\begin{tabular}{|c|c|c|c|c|c|}
\hline & $\begin{array}{l}\text { Bacterial, } \\
\text { median (IQR)* }\end{array}$ & $\begin{array}{l}\text { TB, } \\
\text { median (IQR)* }\end{array}$ & $\begin{array}{l}\text { Unclassified, } \\
\text { median (IQR)* }\end{array}$ & $\begin{array}{l}\text { Total, } \\
\text { median (IQR)* }\end{array}$ & $p$-value \\
\hline & $37(40)$ & $36(40)$ & $18(20)$ & 91 & \\
\hline \multicolumn{6}{|l|}{ Blood investigations } \\
\hline $\mathrm{WCC}^{*}\left(\times 10^{9} / \mathrm{L}\right)$ & $16.6(10.6-27.7)$ & $10.3(7.9-13.1)$ & $14.4(5.0-21.7)$ & $12.0(8.1-23.5)$ & 0.005 \\
\hline CRP (mg/L) & $250.5(188.5-305)$ & $122(75-156)$ & $125.5(54-236)$ & $171(102-257)$ & $<0.001$ \\
\hline PCT (mg/L) & $11.6(3.4-29.4)$ & $0.46(0.24-1.43)$ & $4.8(0.17-14.31)$ & $2.7(0.39-12.73)$ & $<0.001$ \\
\hline \multicolumn{6}{|l|}{ Pleural fluid tests } \\
\hline Protein (g/L) & $46.5(37-51)$ & $55(51-58)$ & $55(47-60)$ & $51.5(42-57)$ & 0.007 \\
\hline LDH (U/L) & $7280(3433-16844)$ & $544(386-820)$ & $1326(358.5-951)$ & $1071(473-855)$ & $<0.001$ \\
\hline Glucose $(\mathrm{mmol} / \mathrm{L})$ & $1.25(0.6-3.15)$ & $4(3-5)$ & $5.05(4-5.6)$ & $3.5(1.7-4.7)$ & $<0.001$ \\
\hline ADA (U/L) & $116.2(59.2-275)$ & $47.1(41.3-58.2)$ & $47.6(36.8-79.4)$ & $56.1(44.2-106.4)$ & $<0.001$ \\
\hline Polymorphs $\left(\times 10^{9} / \mathrm{L}\right)$ & $1340(605-3280)$ & $27(5.5-120)$ & $260(106-400)$ & $133(11-530)$ & $<0.001$ \\
\hline Lymphocytes $\left(\times 10^{9} / \mathrm{L}\right)$ & $460(115-720)$ & $832(419-1522)$ & $400(155-800)$ & $664(224-1185)$ & 0.142 \\
\hline Cytology, $n$ & 31 & 35 & 16 & 82 & \\
\hline Reactive lymphocytes, $n$ (\%) & $11(29.7)$ & $23(63.9)$ & $7(38.9)$ & $41(45.0)$ & 0.044 \\
\hline Neutrophils scattered, $n(\%)$ & $16(43.2)$ & $8(22.2)$ & $6(33.3)$ & $30(33.0)$ & 0.054 \\
\hline
\end{tabular}

Table 5. Outcome data

\begin{tabular}{|c|c|c|c|c|c|}
\hline & $\begin{array}{l}\text { Bacterial, } \\
n(\%)^{*}\end{array}$ & $\begin{array}{l}\text { TB, } \\
n(\%)^{*}\end{array}$ & $\begin{array}{l}\text { Unclassified, } \\
n(\%)^{*}\end{array}$ & $\begin{array}{l}\text { Total, } \\
n(\%)^{*}\end{array}$ & $p$-value \\
\hline Chest drain & $37(100)$ & $21(58.3)$ & $16(88.9)$ & $74(81.3)$ & $<0.001$ \\
\hline Chest drain type, pigtail: hard & $30: 5$ & $18: 0$ & $10: 3$ & $58: 8$ & 0.129 \\
\hline Duration of chest drain, median (IQR) & $6(5.0-11.5)$ & $4(3-6)$ & $4(3-6)$ & $5(3.5-6.0)$ & 0.003 \\
\hline Duration fever (days), median (IQR) & $3(1-5)$ & $0.5(0-2.5)$ & $1(1-4)$ & $1(0-4)$ & 0.055 \\
\hline Length of stay, median (IQR) & $10.5(8.5-17.0)$ & $6(3-8)$ & $9(5-13)$ & $8.5(5-13)$ & $<0.001$ \\
\hline Fibrinolysis & $29(78.4)$ & $6(17.1)$ & $9(50)$ & $44(48.9)$ & 0.001 \\
\hline ICU admission & $7(18.9)$ & 0 & $3(16.7)$ & $10(11.0)$ & 0.013 \\
\hline Surgical drainage & $10(27)$ & $1(2.8)$ & $1(5.56)$ & $12(13.2)$ & 0.007 \\
\hline Bronchopleural fistula & $2(5.6)$ & $1(2.8)$ & 0 & $3(3.3)$ & 0.801 \\
\hline Death & 0 & 0 & 1 & $1(1.1)$ & \\
\hline
\end{tabular}

of pleural drainage reported. A similarly high rate of chest drainage was found in a local study by Ghoor et al. ${ }^{[9]}$ in Johannesburg, SA, who reported $90.8 \%$ chest drainage (including hard drain and pigtail) in their study.

The mean (IQR) length of stay in our present study was 8.5 (5 - 13) days, which is lower than that reported in similar studies in SA. ${ }^{[7,9]}$ Further findings supporting the hypothesis of the unclassified group representing partially treated bacterial infections is the higher frequency of interventions i.e., chest drain (89\%), fibrinolysis (50\%) and longer length of hospital stay, which approaches that of the bacterial group rather than that of the TB group.

\section{Study limitations}

A limitation of the present study is that the molecular-based PCR testing on pleural fluid specimens could not be performed at completion of the study as funding was not yet available. These specimens have been stored and planned for PCR testing at a later stage, which will likely reveal a higher prevalence of bacterial pathogens in the pleural 
fluid samples, either as isolated bacterial infection or co-infections with TB.

Most of the bacterial group were culture-confirmed but only half of the TB group had microbiological confirmation of TB. However, comparison of clinical and laboratory data between groups is consistent with a clinical diagnosis of TB.

Confirmation of PCV vaccination data was limited by unavailable immunisation records at the time of hospital admission.

Study inclusion criteria excluded children with small, clinically insignificant PE that did not require pleural aspiration and drainage. We recognise that this could have led to a selection bias to more severe or advanced cases of PE.

\section{Conclusions}

Our study found that $S$. pneumoniae is an uncommon cause of cultureconfirmed PE in the post-PCV era in SA, simultaneously highlighting the importance of empiric treatment for S. aureus in childhood PE cases. TB is an important cause of $\mathrm{PE}$ in our setting, diagnosed with equal frequency as bacterial PE. We found clinical and laboratory features that are practically helpful in distinguishing TB from bacterial causes of PE in most cases, but in up to $20 \%$ of children presenting with $\mathrm{PE}$, their use in establishing a diagnosis is limited. Molecular testing in routine care will therefore be advantageous in guiding treatment of children where the aetiology of PE is unclassifiable using clinical and routine laboratory investigations.

Declaration. This study was done in partial fulfillment of requirements for MMed in Paediatrics at the University of Cape Town.

Acknowledgements. We would like to thank the patients and their families for willingness to participate in the study and Sr Margherita Prins for assistance with induced sputum collection and logistical support.

Author contributions. LG, MZ conceptualised the study and designed the protocol, collected data and wrote the manuscript. DG, AV, HZ, SC, AA, SKO, DM, NA, and AL assisted with protocol development, data collection, patient recruitment and review of the manuscript. KR performed statistical analysis and revised the manuscript. AV assisted with administration and management of the pleural effusion study. All authors approved the manuscript for publication.

Funding. The study was funded by the UCT Department of Paediatrics Research Award for LG.

Conflicts of interest. None.

1. World Health Organization. Causes of child mortality 2017. Geneva: WHO, 2017 https://www.who.int/gho/child_health/mortality/causes/en/ (accessed 25 June 2019).

2. Munoz-Almagro C, Selva L, Pallares R. Influence of pneumococcal vaccine on the incidence of empyema. Curr Opin Pulm Med 2010;16(4):394-398. https://doi. org/10.1097/MCP.0b013e328338c19f

3. Statistics South Africa. Mortality and causes of death in South Africa, 2016: Findings from death notification. Pretoria: Stats SA, 2018. https://www.statssa.gov. za/publications/P03093/P030932016.pdf (accessed 24 June 2019).

4. Erlichman I, Breuer O, Shoseyov D, et al. Complicated community acquired pneumonia in childhood: Different types, clinical course, and outcome. Paediatr Pulmonol 2016;52(2):247-254. https://doi.org/10.1002/pul.23523

5. Madhi F, Levy C, Morin L, et al. Change in bacterial causes of communityacquired parapneumonic effusion and pleural empyema in children 6 years after 13-valent pneumococcal conjugate vaccine implementation. J Paediatric Inf Dis Soc 2019;8(5):474-477. https://doi.org/10.1093/jpids/piy103
6. Liese JG, Schoen C, van der Linden M, et al. Changes in the incidence and bacterial aetiology of paediatric parapneumonic pleural effusions/empyema in Germany, 20102017: A nationwide surveillance study. Clin Microbiol Infect 2019;25(7):857-864. https://doi.org/10.1016/j.cmi.2018.10.020

7. Zampoli M, Kappos A, Wolter N, et al. Aetiology and incidence of pleural empyema in South African children. Paediatr Infect Dis J 2015;34(12):1305-1310. https://doi. org/10.1097/inf.0000000000000880

8. Zampoli M, Chaya S, J. Zar H. Empyema in children: Update of aetiology, diagnosis, and management approaches. Curr Pulmonol Rep 2017;6(1):16-25. https://doi. org/10.1007/s13665-017-0161-4

9. Ghoor A, Mabaso T, Mopeli K, et al. Empyema in children hospitalised at Chris Hani Baragwanath Academic Hospital, Johannesburg, South Africa: A retrospective study. S Afr Med J 2018;108(12):1055-1058. https://doi.org/10.7196/samj.2018. v108i12.13099

10. World Health Organization. Global Tuberculosis Report 2019. Geneva: WHO, 2020. https://apps.who.int/iris/bitstream/handle/10665/329368/9789241565714-eng. pdf?ua $=1$ (accessed 10 December 2020)

11. Detjen AK, DiNardo AR, Leyden J, et al. Xpert MTB/RIF assay for the diagnosis of pulmonary tuberculosis in children: A systematic review and meta-analysis. Lancet Resp Med 2015;3(6):451-461. https://doi.org/10.1016/S2213-2600(15)00095-8

12. Chakravorty S, Simmons AM, Rowneki M, et al. The new Xpert MTB/RIF Ultra: Improving detection of Mycobacterium tuberculosis and resistance to rifampin in an assay suitable for point-of-care testing. mBio 2017;8(4):e00812-e00817. https://doi. org/10.1128/mBio.00812-17

13. Bisognin F, Lombardi G, Lombardo D, Re MC, Dal Monte P. Improvement of Mycobacterium tuberculosis detection by Xpert MTB/RIF Ultra: A head-to-head comparison on Xpert-negative samples. PLoS One 2018;13(8):e0201934. https://doi. org/10.1371/journal.pone.0201934

14. Raizada N, Sachdeva KS, Swaminathan S, et al. Piloting upfront Xpert MTB/RIF testing on various specimens under programmatic conditions for diagnosis of TB \& DR-TB in paediatric population. PLoS ONE 2015;10(10):e0140375. https://doi. org/10.1371/journal.pone.0140375

15. Scott LE, Beylis N, Nicol M, et al. Diagnostic accuracy of Xpert MTB/RIF for extrapulmonary tuberculosis specimens: Establishing a laboratory testing algorithm for South Africa. J Clin Microbiol 2014;52(6):1818-1823. https://doi.org/10.1128/ jcm.03553-13

16. Sehgal IS, Dhooria S, Aggarwal AN, et al. Diagnostic performance of Xpert MTB/RIF in tuberculous pleural effusion: Systematic review and meta-analysis. J Clin Microbiol 2016;54(4):1133-1136. https://doi.org/10.1128/JCM.03205-15

17. Kohli M, Schiller I, Dendukuri N, et al. Xpert MTB/RIF assay for extrapulmonary tuberculosis and rifampicin resistance. Cochrane Datab Syst Rev 2018;8(8):CD012768. https://doi.org/10.1002/14651858.CD012768.pub2

18. Huo ZY, Peng L. Is Xpert MTB/RIF appropriate for diagnosing tuberculous pleurisy with pleural fluid samples? A systematic review. BMC Infect Dis 2018;18(1):284. https://doi.org/10.1186/s12879-018-3196-4

19. Graham SM, Cuevas LE, Jean-Philippe P, et al. Clinical case definitions for classification of intrathoracic tuberculosis in children: An update. Clin Infect Dis 2015;61(3):S179-S187. https://doi.org/10.1093/cid/civ581

20. National Department of Health. Expanded programme on immunisation - EPI (SA) revised childhood immunisation schedule from December 2015. Pretoria: NDoH, 2015. http://www.health.gov.za/immunization/ (accessed 12 December 2020).

21. Blaschke AJ, Heyrend C, Byington CL, et al. Molecular analysis improves pathogen identification and epidemiologic study of paediatric parapneumonic empyema. Paediatr Infect Dis J 2011;30(4):289-294. https://doi.org/10.1097/ INF.0b013e3182002d14

22. Oliwa JN, Karumbi JM, Marais BJ, Madhi SA, Graham SM. Tuberculosis as a cause or comorbidity of childhood pneumonia in tuberculosis-endemic areas: A systematic review. Lancet Resp Med 2015;3(3):235-243. https://doi.org/10.1016/S22132600(15)00028-4

23. Porcel JM. Advances in the diagnosis of tuberculous pleuritis. Ann Transl Med 2016;4(15):282. https://doi.org/10.21037/atm.2016.07.23

24. Valdés L, Alvarez D, San José E, et al. Value of adenosine deaminase in the diagnosis of tuberculous pleural effusions in young patients in a region of high prevalence of tuberculosis. Thorax 1995;50(6):600-603. https://doi.org/10.1136\%2Fthx.50.6.600

25. Porcel JM, Esquerda A, Bielsa S. Diagnostic performance of adenosine deaminase activity in pleural fluid: A single-center experience with over 2100 consecutive patients. Eur J Intern Med 2010;21(5):419-423. https://doi.org/10.1016/j.ejim.2010.03.011

26. Segura RM. Useful clinical biological markers in diagnosis of pleural effusions in children. Paediatr Respir Rev 2004;5(Suppl A):S205-S212. https://doi.org/10.1016/ s1526-0542(04)90039-5

27. Soares J, Redding GJ. Pleural disease in infants and children: Management updates. Curr Pulmonol Rep 2016;5(1):28-34.https://doi.org/10.1007/s13665-016-0134-Z

Accepted 27 September 2021. 